\title{
Historical Perspective and Future Direction of Blood Vessel Developments
}

\author{
Sashka Dimitrievska ${ }^{1,2}$ and Laura E. Niklason ${ }^{2,3}$ \\ ${ }^{1}$ Howard Hughes Medical Institute, Chevy Chase, Maryland 20815 \\ ${ }^{2}$ Department of Biomedical Engineering, Yale University, New Haven, Connecticut 06520 \\ ${ }^{3}$ Department of Anesthesiology, Yale University, New Haven, Connecticut 06520 \\ Correspondence: laura.niklason@yale.edu
}

Over the past 40 years, remarkable advances have been made in our understanding of successful blood vessel regeneration, starting with the failures of early tissue-engineered vascular grafts designed using isolated components or molecules, such as collagen gels. The vascular tissue engineers are today better educated and have steered ongoing research developments toward clinical developments of more complete vascular grafts that replicate the multitude of specialized arterial aspects required for function.

\begin{abstract}
In the United States, $40 \%$ of all deaths are caused by cardiovascular disease. More than half of these incidents are a direct result of coronary artery disease (Mozaffarian et al. 2014). One of the lifesaving coronary heart disease treatments is the coronary artery bypass procedure of which more than 500,000 are performed annually (Mozaffarian et al. 2014). This review describes the current developmental pipeline for vascular grafts, along with their relative strengths and failure modes.
\end{abstract}

\section{BIOLOGY OF BLOOD VESSELS}

Blood vessels form compact closed circulatory circuits that infiltrate most tissues of the body, distributing nutrients, oxygen, and waste products as well as transporting cells, proteins, and signaling factors of the immune system. Of three types of blood vessels, arteries are the largest and most robust, and their bypass in states of disease is often required to restore healthy blood flow (Kakisis et al. 2005). To fulfill their physiological requirements, arteries have a trilayered structure where each arterial layer is responsible for an independent yet essential function. Starting from the lumen and moving outward: the inti$\mathrm{ma}$ is responsible for the antithrombogenic aspect; the media is responsible for the mechanical strength; and the adventitia imparts vascularization and autonomic control (Fig. 1A) (FauvelLafève 1999).

The intima consists of a monolayer of endothelial cells (ECs) of about $1 \mu \mathrm{m}$ thickness. The ECs are in intimate contact with the bloodstream and are responsible for preventing thrombosis via active and passive mechanisms (Fauvel-Lafève 1999). The active anticoagulant mediators are often released into the circulation, and consist of various secreted prostacy-

Editor: Joseph P. Vacanti

Additional Perspectives on Tissue Engineering and Regenerative Medicine available at www.perspectivesinmedicine.org

Copyright (C) 2018 Cold Spring Harbor Laboratory Press; all rights reserved; doi: 10.1101/cshperspect.a025742

Cite this article as Cold Spring Harb Perspect Med 2018;8:a025742 


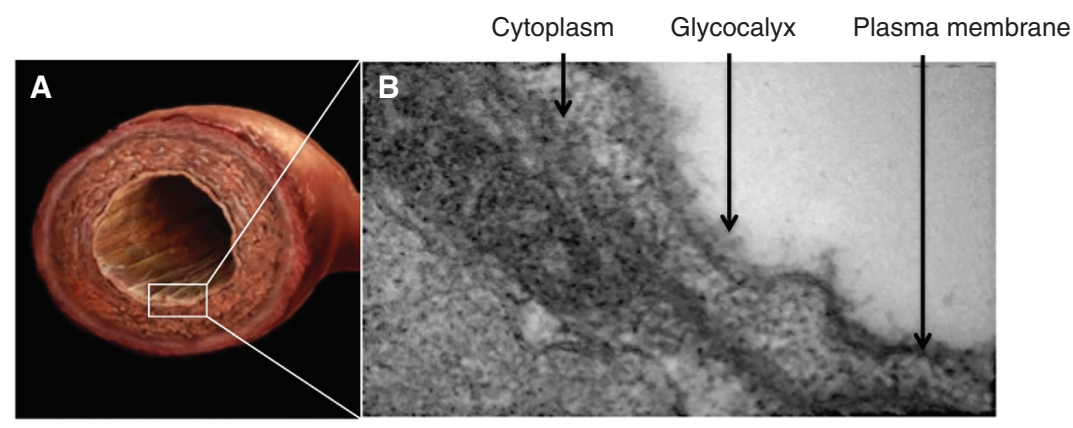

Figure 1. Structure of blood vessels. (A) Excised rat aorta showing the trilayered arterial structure. (B) Transmission electron microscopy (TEM) image of vessel showing a cross-section of an abdominal aorta. The image is focused on the endothelial cells (ECs) lining the intima and the EC-associated glycocalyx brush-like structure.

clins, nitric oxide, and tissue plasminogen activator. EC's passive anticoagulant properties are imparted by the endothelial glycocalyx (Fig. $1 \mathrm{~B})$, which is a mesh-like structure bound on the EC surface containing heparan sulfate proteoglycans and which shields the blood from the thrombogenic basement membrane (van den Berg et al. 2006). The glycocalyx is made up of glycosaminoglycans (GAGs), of which heparan sulfate (HS) is the primary structural component, serving as a potent negative regulator of coagulation. The active EC anticoagulant properties combined with the passive glycocalyx impart a nonthrombogenic surface to contact the circulating blood (Reitsma et al. 2007).

ECs are attached onto a basement membrane, which is adjacent to the subendothelial connective tissue, which is highly thrombogenic because of its collagenous nature (Reitsma et al. 2007). Although thrombogenic when exposed, the subendothelial connective tissue provides the artery's mechanical functionality (FauvelLafève 1999). This mechanical functionality is primarily attributed to the dense extracellular matrix (ECM) deposited by the smooth muscle cells (SMCs) of the medial layer.

\section{REQUIREMENTS FOR BLOOD VESSELS SUBSTITUTES AND DESIGN CRITERIA}

Much of arterial structure and function is derived from its varied composition at the bimolecular level. Engineered grafts that have been designed using isolated components or molecules-such as collagen gels-have failed to replicate the multitude of specialized arterial aspects that are required for function. Often, engineered vascular grafts that offer ideal mechanical properties suffer from surface thrombogenicity, or vice versa. Not surprisingly, therefore, the patient's own blood vessels still remain the most successful arterial replacements. However, autologous vessels are often not an option for patients in need of an arterial replacement, because of prior harvesting or disease-associated vascular damage, prompting the ongoing search for an alternate vascular replacement (Kakisis et al. 2005).

When considering the requirements of a functional tissue replacement, the attempt to mimic the defining characteristics of native arteries is paramount. Current vascular engineering requirements are in large part inspired by the design features of native arteries. As outlined in Table 1, the following key requirements should be met to ensure success: (1) size (inner lumen diameter and length) of the tubular conduit must be matched to the application; (2) mechanical properties of the artery being bypassed must be matched, as least as far as ultimate tensile strength and preferably as far as compliance; (3) thrombogenicity of the graft must be low (enhanced blood compatibility); and (4) regeneration/integration potential, to ensure graft longevity. Each aspect contributes independently toward the long-term functional success of the vascular graft. 
Blood Vessel Developments

Table 1. Requirements of an ideal vascular graft

\begin{tabular}{|c|c|c|c|c|}
\hline Design criteria & Main guidelines & Approaches & Function & $\begin{array}{l}\text { Crucial } \\
\text { timeframe }\end{array}$ \\
\hline $\begin{array}{l}\text { Mechanical } \\
\text { properties }\end{array}$ & $\begin{array}{l}\text { Compliance and } \\
\text { ultimate tensile } \\
\text { properties similar to } \\
\text { native vessel }\end{array}$ & $\begin{array}{l}\text { Incorporate mature } \\
\text { matrix or synthetics }\end{array}$ & $\begin{array}{l}\text { Prevents dilatation, } \\
\text { rupture, bleeding }\end{array}$ & $\begin{array}{l}\text { Immediate } \\
\text { and long } \\
\text { term }\end{array}$ \\
\hline Thrombogenicity & Anticoagulant surface & $\begin{array}{l}\text { Chemical coating; } \\
\text { endothelial cell } \\
\text { seeding }\end{array}$ & $\begin{array}{l}\text { Prevents blood } \\
\text { clotting }\end{array}$ & $\begin{array}{l}\text { Short to } \\
\text { midterm }\end{array}$ \\
\hline Structure & $\begin{array}{l}\text { Size (inner lumen } \\
\text { diameter and length) } \\
\text { match to native } \\
\text { arteries }\end{array}$ & $\begin{array}{l}\text { Various sizes of } \\
\text { scaffolds or } \\
\text { mandrels }\end{array}$ & $\begin{array}{l}\text { Conducts blood } \\
\text { without excessive } \\
\text { turbulence or } \\
\text { resistance }\end{array}$ & $\begin{array}{l}\text { Immediate } \\
\text { and long } \\
\text { term }\end{array}$ \\
\hline Regeneration & $\begin{array}{l}\text { Integration with the } \\
\text { native tissue, both at } \\
\text { anastomosis and } \\
\text { abluminally }\end{array}$ & $\begin{array}{l}\text { Avoid heavy cross- } \\
\text { linking, and non- } \\
\text { collagen-based } \\
\text { building blocks }\end{array}$ & $\begin{array}{l}\text { Prevents both blood } \\
\text { clotting and intimal } \\
\text { hyperplasia-mid- } \\
\text { term }\end{array}$ & $\begin{array}{l}\text { Mid- to long } \\
\text { term }\end{array}$ \\
\hline
\end{tabular}

Mechanical mismatch between the graft and native blood vessel contributes both to thrombogenicity and to intimal hyperplasia via two distinct mechanisms. The mechanical mismatch creates local discontinuities in blood-flow velocity, resulting in stagnant regions of blood flow increasing the thrombogenicity (Teebken and Haverich 2002). On the other hand, intimal hyperplasia results as an adaptive remodeling response that is partially driven by the mismatch in compliance. Hence, the compliance, burst pressure, kink, and compression resistance are important matching parameters. Furthermore, suitable ultimate tensile properties and moduli are important to avoid long-term dilatation, aneurysm formation, and potential rupture.

Antithrombogenicity is important, because thrombus formation eventually leads to thrombotic graft failure, a failure risk that is substantially increased in small diameter grafts (Seifu et al. 2013). The increased thrombogenic failure risk in small diameter applications is caused by the increased graft-surface-to-blood-volume ratio, resulting in increased activation of blood elements. The reduced blood flow in small vessels also causes an increase in contact time with the luminal graft surfaces.

The size and shape match is important for two reasons. From a surgical perspective, the size match is essential to allow successful anas- tomosis between the native and implanted vessel and restoration of blood flow. The shape and angle match of the anastomotic junction allows restoration of blood flow without excessive turbulence or hydraulic pressure drop. A size mismatch between the implant and artery may create vortices or stagnating flow, both of which decrease wall shear stress and may lead to eventual graft occlusion.

Regeneration of the implanted graft is important, because the long-term integration of the graft within the native vasculature will also largely be responsible for its success. Avoidance of long-term foreign body response, such as that elicited by nondegradable synthetics such as polytetrafluoroethylene (PTFE), is important for biocompatibility in the vascular system. Grafts that are composed of extracellular matrix proteins must be invested with live cells to maintain the matrix elements, which have finite half-lives on the order of months to years.

\section{TYPES OF DECELLULARIZED VASCULAR SCAFFOLDS}

Decellularized vascular grafts have seen an increase in popularity, because they are thought to provide a supportive microenvironment for the above-described functional parameters. Depending on the species of origin, decellularized 


\section{S. Dimitrievska and L.E. Niklason}

vascular scaffolds are thought to have lower immunogenicity than intact tissues and minimal immunogenicity if the extracellular matrix (ECM) is of the same species as the recipient. Matrix-based materials allow the production of mechanically compliant grafts, and have the advantage of being readily available to patients who require expeditious intervention (Quint et al. 2011). The main subgroups are laboratory grown (or tissue engineered), and native human and animal origin vascular tissue scaffolds that are then decellularized.

Decellularization is the process of removing the cells from the tissue, sparing only the ECM. It is accomplished by washing the construct with a combination of detergents, protease inhibitors and buffers, as well as enzymes to remove specific cellular components in some applications (Quint et al. 2011; Dimitrievska et al. 2015). The decellularization procedure removes most cellular antigens that are responsible for foreign recognition, creating a conserved and well-tolerated ECM structure (Fig. 2). Hence, decellularized scaffolds largely lack immunogenicity, allowing transplantation of the constructs within species without the use of lifelong immunosuppressing medication. While there are no examples non-cross-linked, xenogeneic matrices being used successfully in the arterial system, there are multiple successful examples of allogeneic matrices in this setting. In addition, provided that the decellularization process is undertaken with sufficient care, the starting mechanical properties of the tissues
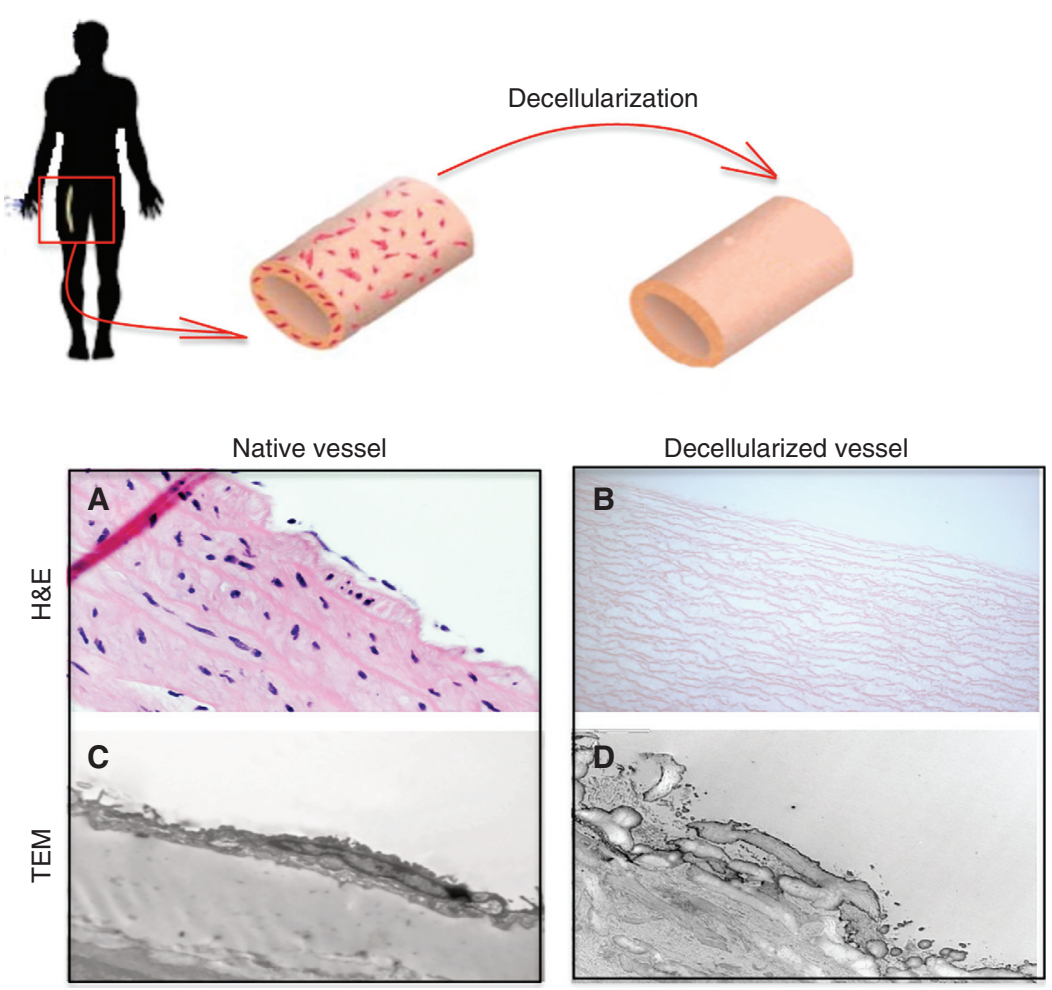

Figure 2. Schematic representation of a decellularization procedure from a human femoral artery and corresponding histological images. (A) The explanted vessel haematoxylin and eosin (H\&E) where the endothelial cells (ECs) and the smooth muscle cells (SMCs) lining the vascular wall are shown. (B) Post-successful decellularization, all cells are removed, showing only ECM layers via the H\&E stain. $(C)$ Transmission electron microscopy (TEM) analysis of the basement membrane in the native vessel shows the EC lining the continuous basement membrane. (D) Post-successful decellularization, ECs are removed at the expense of a damaged basement membrane. 
are retained following the decellularization procedure.

\section{DECELLULARIZED XENOGRAFTS AND ALLOGRAFTS}

The starting materials to construct arterial grafts span human umbilical and femoral arteries; animal vasculature such as porcine carotid arteries and abdominal aorta, and the flat decellularized porcine small intestinal submucosa (SIS) (Teebken et al. 2000; Dohmen et al. 2002, 2007; Walles et al. 2003; McFetridge et al. 2004; Derham et al. 2008; Narita et al. 2008; Stapleton et al. 2008), among others. Independent of the sourced origin, decellularized native vascular grafts are constructed as follows: (1) explanation of the scaffolds of interest from the donor; (2) mechanical removal of the surrounding tissues; and (3) tissue-appropriate decellularization and sterilization. For example, to prepare decellularized scaffolds from arteries (both from human and animal origin) the abluminal fat tissue is removed before decellularization (Teebken et al. 2000; Stapleton et al. 2008), whereas in the case of SIS, the mucosa and muscle are isolated from the small intestine before decellularization (Narita et al. 2008). The decellularization step that is then undertaken varies by tissue type and donor species (Fig. 2).

\section{Decellularized Xenografts}

Decellularized porcine scaffolds' mechanical properties (tensile strength, compliance, and burst pressures) match the human saphenous vein fairly well, which has encouraged clinical development (Teebken et al. 2000; Dohmen et al. 2002, 2007; McFetridge et al. 2004; Derham et al. 2008; Dimitrievska et al. 2015). The commonly used xenografts of porcine origin are ureters and heart valves. In fact, xenograft heart valves of porcine origin that are treated with glutaraldehyde and mounted in a rigid stent are very clinically successful (Dohmen et al. 2002, 2007). This has motivated the development of various other decellularized porcine matrices for use as small diameter vascular grafts, but success there has been more limited (Teebken et al.
2000; Dohmen et al. 2002, 2007; McFetridge et al. 2004; Derham et al. 2008; Dimitrievska et al. 2015). Decellularized porcine ureter scaffolds were found to be highly thrombogenic, especially in the small diameter setting (Walles et al. 2003). The driving cause of this thrombogenicity is probably similar to all other decellularized scaffolds of animal origin. The decellularization procedure exposes collagen, which is one of the most thrombogenic components of the subendothelial matrix responsible for the initiation of platelet activation and adhesion. Therefore, although almost perfectly matched from a mechanical standpoint, these grafts are still lacking the antithrombogenicity dimension required for a successful implantation in small calibers.

A second pitfall of xenografts, especially xenografts of aortic origin, has been limited cell migration into the scaffolds, probably because of the very tight matrix organization specific to the aortic structure (combined with glutaraldehyde fixation effects) (Walles et al. 2003). To enhance the cellular infiltration into xenografts, elastin and collagen have been selectively removed using elastin- or collagen-specific enzymes. However, even in selectively depleted scaffolds with increased porosity, SMCs have failed to infiltrate (Simionescu et al. 2006). These results indicate that scaffold composition and architecture need to be more than just "cellfriendly" but also should contain migratory cell signals and an overall architecture that can aid in driving cells into the scaffolds.

An additional hurdle of xenografts in vascular applications is their occasional catastrophic failure in pediatric patients. Porcine decellularized valve conduits produced by the SynerGraft technology (CryoLife) showed immunologic compatibility in preclinical animal studies but when implanted into four children, failed catastrophically when three children died (Simon et al. 2003). This failure has been associated with strong immune rejection and inflammation mechanisms, typical of antigen-mediated immunity. It has been postulated that the reason for the strong inflammation and rejection of these implants was that in the decellularization procedure, the antigenic cellular components were incompletely removed. This study exem- 
plifies the importance of the successful removal of all cellular materials before a xenograft transplantation in humans, which has also prompted the Food and Drug Administration (FDA) to increase the characterization of decellularized xenografts before human studies.

\section{Decellularized Human Vascular Allografts}

Cryopreserved vascular allografts are widely used for cardiac and vascular peripheral surgery (Hartranft et al. 2014). The cryopreservation technique retains some fibroblasts' viability, meaning these are not fully decellularized grafts. Although the cell presence allows some regeneration capacity of the graft, the preserved cells also show preserved antigenicity, leading to macrophages and plasma cells infiltrating the graft, with subsequent release of proteolytic enzymes. These negative immune responses can result in disruption of the anastomosis, which combined with the additional infections lead to early postoperative death in $13 \%-25 \%$ cases, and an amputation rate of 5\% (Hartranft et al. 2014).

In related vascular applications, human cryopreserved allografts were implanted as hemodialysis access grafts and seem less prone to fibrosis, calcification, and degeneration as compared to their xenograft counterparts. Particularly CryoLife (Synergraft) implanted cryopreserved cadaver femoral allografts decellularized in an antigen-reduced manner and showed comparative results to PTFE grafts (McAllister et al. 2009; Mount et al. 2014). CryoLife also produced SynerGraft aortic valve conduit from human valves that were decellularized before cryopreservation. They were implanted into 22 patients as aortic valve conduits and showed lack of immunoreactivity, indicating successful antigen removal in the decellularization process (Zehr et al. 2005).

In addition, decellularized small-diameter vascular allografts are being developed in various animal models for eventual clinical translation. Decellularized human umbilical veins have showed cellular integration and mechanical property maintenance postimplantation (Assmann et al. 2013; Cittadella et al. 2013; Pennel et al. 2014). However, decellularized human umbilical veins functionality has only been tested in the very permissive nude rat model, and only for short implantation periods of 8 weeks (Assmann et al. 2013).

\section{TISSUE-ENGINEERED VASCULAR GRAFTS}

Over the past several decades, tissue-engineered vascular grafts (TEVGs) have been studied as a means to develop a successful vessel that integrates with native vasculature and maintains patency in small-diameter applications. Different approaches have resulted in important advancements of the field, all by conceptually striving to meet the design criteria that are described in Table 1.

The ideal scaffold for vascular engineering has to provide a template SMC and EC growth/ migration, as well as ECM secretion. If implanted as a structural element of the graft, the scaffold must also possess the mechanical strength and compliance necessary to withstand the pulsatile pressures of the vascular system. To date, the scaffolding approaches that have had most success are based on one of the following three main approaches: degradable polymeric scaffolds, extracellular matrix-based scaffolds, and cell sheets (which contain little or no synthetic scaffold material) (Fig. 3).

\section{Extracellular Matrix- and Protein-Based Scaffolds}

Tissue-engineered grafts built from purified forms of extracellular matrix proteins mimics to some degree the native artery where SMCs are embedded in the ECM. Typically, ECM components are prepared in a gel-like solution, and injected in a tubular mold in combination with cells. The gel is allowed to solidify in the tubular mold, thereby entrapping the cells. Using ECM - such as collagen or fibrin - as the scaffold offers the advantage of providing matrix stimuli recognized by cells, allowing them to bind and remodel the scaffold and secrete more ECM as dictated by soluble and mechanical cues. This approach is historically important for TEVG development, because it was the first TEVG strategy reported (Weinberg and Bell 


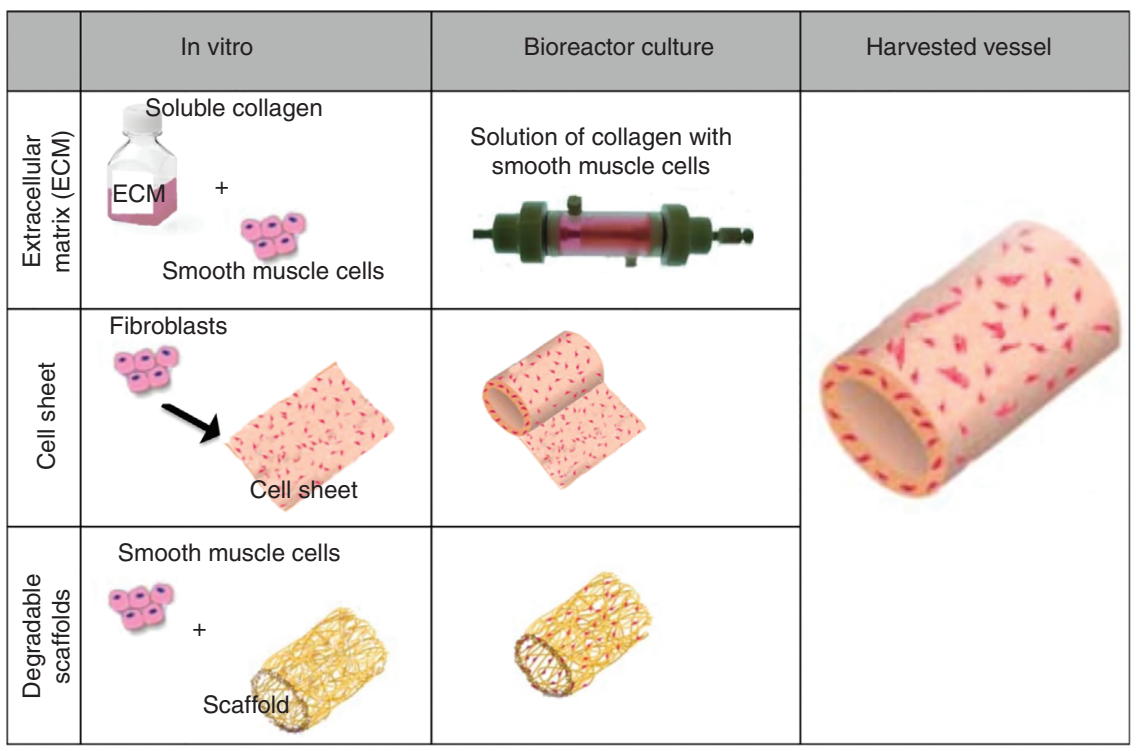

Figure 3. Simplified summary of the three most common tissue-engineering approaches that allow for customizable control over the 3D geometry of the resulting graft.

1986). However, this approach is plagued by problems with low mechanical properties: ECM scaffold gels are typically weak and, oftentimes, little additional ECM is deposited by the cultured cells. As a result, gel ECM-based grafts have a burst pressure as low as $40 \mathrm{~mm} \mathrm{Hg}$, which cannot support the physical loads of the cardiovascular system (as a reference point, native human saphenous veins rupture at $\sim 2000 \mathrm{~mm}$ $\mathrm{Hg}$ ) (Weinberg and Bell 1986; Mironov et al. 2005; Belkin et al. 2010; Seifu et al. 2013). Many strategies to improve the mechanical properties of the gel scaffolds, such as reinforcing "sleeves," replacement of the collagen with fibrin gels (fibrinogen and thrombin), glycation, cross-linking of the matrices, or dynamic mechanical stimulation in vitro have been developed (Grassl et al. 2003). Recently, the Tranquillo group generated fibrin gel-based smalldiameter vascular grafts using human dermal fibroblasts with increased burst strength, suggesting potential use in arterial reconstruction (Syedain et al. 2011). However, despite the notable mechanical improvement, this approach has not progressed to human implantation (Weinberg and Bell 1986; Mironov et al. 2005; Belkin et al. 2010; Seifu et al. 2013).

\section{Cell Sheets}

This strategy allows the cells themselves to produce the scaffold, resulting in a completely biological TEVG with impressive mechanical properties. L'Heureux pioneered this strategy using autologous fibroblasts grown on flat culture plates in the presence of elevated ascorbic acid (to increase collagen synthesis), which results in fibroblasts sheets embedded in fibrillar collagenous ECM (Mount et al. 2014). The sheets are then wrapped around a tubular mandrel, allowing the individual plies to fuse together, creating tubular structures. The initial safety of cell-sheet TEVG has been shown in clinical trials by Cytograft using vessels produced from a cell bank (Lifeline grafts) implanted as arteriovenous shunts for hemodialysis access (Wystrychowski et al. 2014).

\section{Degradable Polymeric Scaffolds}

The most commonly used degradable polymer scaffolds in vascular regeneration are polycaprolactone (PCL), polyglycolic acid (PGA), polylactic acid (PLA), and copolymers thereof. The polymer is typically processed into a porous $3 \mathrm{D}$ 
tubular structure onto which cells are seeded and allowed to invade. Niklason has moved this approach from the academic setting into currently ongoing human clinical trials in dialysis access (McKee et al. 2003; Dahl et al. 2011). In this approach, a PGA tubular graft is seeded with SMC and cultured for 8 weeks under pulsatile conditions. The PGA scaffold initially withstands the mechanical stresses, but loses strength over time as it degrades, thereby gradually loading the cells with physiological stresses. This stimulates the cells to synthesize substantial ECM, thereby achieving sufficient mechanical strength in the absence of the PGA scaffold. After 8 weeks of culture in a pulsatile bioreactor, size-customizable TEVG with implantable mechanical properties are harvested.

Prior to implantation, the engineered TEVG may be decellularized, allowing transplantation of the constructs into allogeneic recipients. The advantage of this approach is that vascular grafts can be created with the desired mechanical properties and dimensions, ahead of time. One human donor provides a cell bank large enough to produce 70 or more tissue-engineered vascular grafts (McKee et al. 2003; Dahl et al. 2011). In comparison to native decellularized scaffolds (of animal or human origin) where branches must be ligated to create a continuous conduit, the engineered structures have no branches and are not tapered. Also, the diameter is a well-controlled parameter in engineered structures, allowing an exact match with the native bypassed artery. Therefore, combining the TEVG approach with decellularization produces size-customizable grafts, with suitable mechanical properties. This is an important advance in the vascular regeneration field, where cellular products cannot be stored long-term and must be custom-made for each patient.

\section{Decellularization Characteristics Going Forward into Vascular Human Clinical Applications}

The rationale for xenograft, allograft, and TEVG decellularization is that removal of the native cells will remove most or all of the important antigenicity of the implant. Decellularization is validated by visually verifying the absence of cell nuclei using histologic analysis. However, the catastrophic SynerGraft story revealed that histological analysis of implants is insufficient, because the failed grafts on histological analysis revealed no detectable residual cells or cell nuclei. These results suggest that decellularization in some cases may disrupt the cells without adequately removing the antigenic proteins responsible for immunological responses. Therefore, decellularization requires validation of residual amounts of cellular protein and DNA that remain in the construct to have a reliable benchmark for understanding and preventing immunogenicity.

Unfortunately, to date, it is still unclear to what extent a decellularization procedure can or should remove noncellular components of the extracellular matrix. Of primary concern among known xenogeneic antigens is galactose- $\alpha$-(1,3)-galactose ( $\alpha$-gal), which is widely accepted to be the first barrier to discordant xenotransplantation (Baumann et al. 2004). It is estimated that as much as $1 \%$ of natural human immunoglobulinG (IgG) is directed against the $\alpha$-gal moiety (Baumann et al. 2004). Glutaraldehyde treatment of xenografts can reduce immunogenicity by cross-linking the active $\alpha$-gal moities, but glutaraldehyde has been shown to induce its own series of undesirable inflammatory reactions in the vasculature. Glutaraldehyde-treated cardiac implants have undesirable reactions ranging from endothelialization delays, to toxic aortic wall damage, inducing scar formation and inflammatory reactions (Simionescu et al. 2011). Therefore, complete decellularization of xenografts in particular is an absolute necessity to ensure their success.

\section{FUNCTION AND COMPLICATIONS OF TRANSPLANTED VESSELS}

Arterial bypass is indicated to delay unfavorable events such as tissue ischemia, recurrent angina, myocardial infarction, or death (Hawkes et al. 2006). In the coronary and peripheral arterial systems, the most successful graft remains the autologous saphenous vein, but even the highest patency rate of autologous grafts is 60\% at 10 
years in the coronary vasculature (Hawkes et al. 2006). The patency rate is dramatically lower with synthetic substitutes, particularly in small diameter $(<6 \mathrm{~mm})$ applications where only $50 \%$ of synthetic grafts survive 2 years in the peripheral circulation (such grafts are essentially not used in the coronary system because of rapid thrombosis) (Hawkes et al. 2006).

Broadly speaking, graft failures are classified into early, midterm, and late failure. Early failures (within 30 days after the implantation) are related to acute thrombosis. Midterm failures (3 months to 2 years after the implantation) result from lumen occlusion caused by intimal hyperplasia, whereas late failures ( $>2$ years) are often related to recurrent atherosclerotic disease. It is known that the disappointing patency rate of small diameter grafts is primarily because of the development of anastomotic intimal hyperplasia (IH) and thrombus formation (Hawkes et al. 2006). Intimal hyperplasia refers to the thickening of the intima of the implanted graft or of the adjacent neighboring native vessel (Glynn and Hinds 2014). The intimal thickening can grow to fully obstruct blood flow via the migration and proliferation of SMC, combined with increased matrix production. While acute thrombosis also leads to graft occlusion, thrombosis is driven by a different mechanism. It results from a failure of hemostatic balance, which is normally maintained by a complex series of coagulation reactions that involve both systemic and local factors primarily driven by the endothelium.

Failure Mechanisms Specific to Decellularized Native and Tissue-Engineered Vascular Grafts

It is currently believed that the principle failure mode in acellular grafts is via acute thrombosis rather than $\mathrm{IH}$ (Owens et al. 2015). The reason is in the arterial circulation; thrombosis is primarily a platelet-driven event because platelets activate by receptor binding of the collagen moieties (Owens et al. 2015). The platelet activation response to collagen is amplified, resulting in platelet aggregation (de Mel et al. 2012; Rees et al. 2008). In healthy vasculature, platelet adhesion to collagen is prevented by the EC lining, which shields the blood from the vascular wall beneath. However, postimplantation and before reendothelialization in vivo, decellularized grafts are only composed of exposed collagen in the wall of the graft, which renders them vulnerable to platelet activation.

In an effort to mitigate the cascade of events leading to thrombosis, much research has been focused on passivation of the vascular graft's surface via biological and chemical approaches. The biological avenue consists of seeding EC before implantation and growing the ECs until a confluent layer is reached, thereby providing a "functional" vessel. The chemical strategy consist of coating the luminal surface with various natural and synthetic materials and moieties that would reduce the electrostatic interactions at the blood-graft interface, attract circulating endothelial progenitors, or, in particular, inhibit platelet activation and adhesion (Fig. 4).

\section{Endothelial Cell Seeding}

Endothelial cell seeding to improve small diameter vascular graft patency was first proposed in the 1970s. Many seeding and EC sourcing strategies have been attempted as a luminal vessel

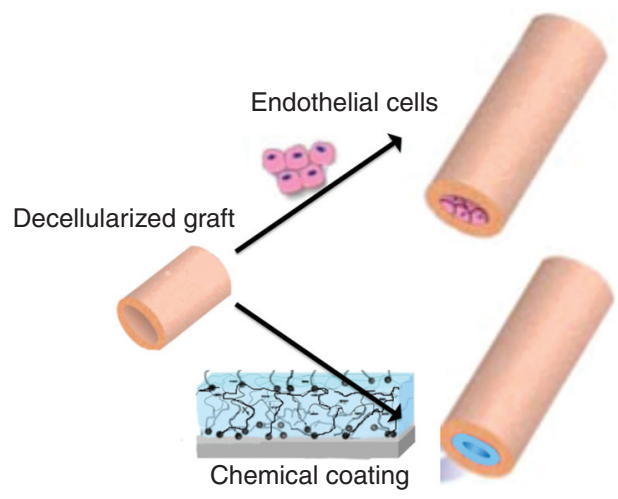

Figure 4. Schematic representation of the main two approaches for producing an antithrombogenic surface in decellularized vascular grafts. The top drawing represents the biological avenue of seeding endothelial cells (ECs) growing before implantation. The bottom panel represents the chemical strategy, wherein the decellularized surface is "coated," thereby hiding the collagen from the circulating blood, inhibiting the platelet activation. 
lining in an attempt to reduce thrombosis, inflammation, and hyperplasia (Dahl et al. 2011; Simionescu et al. 2011). Depending on the species under study, human arterial or umbilical vein endothelial cells (HUVECs) have been used, although bovine, canine, and porcine ECs have also been used (Bhattacharya et al. 2000; Teebken et al. 2000; Dohmen et al. 2002, 2007; McFetridge et al. 2004; Kakisis et al. 2005; Hashi et al. 2007; Yang et al. 2010; Simionescu et al. 2011; Glynn and Hinds 2014).

The most notable positive clinical study of EC graft seeding involved the concept brought forth by vascular surgeons Malcolm Herring and Linda Graham, in which ECs are seeded onto the meshwork of synthetic expanded polytetrafluoroethylene (ePTFE) grafts (Deutsch et al. 2009). Over 400 human subjects were implanted with patient's own endothelialized ePTFE grafts. Despite initial enthusiasm, this clinical study showed only marginal improvement over nonendothelialized ePTFE surfaces, with $74 \%$ patency at 7 years. In addition, the primary method of failure remained thrombosis, correlating EC seeding with a partial reduction in early thrombosis, but without mid- or long-term failure prevention.

These results were somewhat surprising, given the very positive animal study outcomes of EC-seeded grafts (Deutsch et al. 2009). In search of an explanation for the discrepancy between animal studies and clinical trials, insufficient seeding densities on the clinical grafts seemed plausible. However, this study revealed that the failed grafts remained endothelialized, while showing highly inflammatory subendothelial areas and hyperplastic occlusions rather than the absence of an endothelium. One other possible explanation of the insufficient thrombogenic protection is the underlying biology of the static culture of endothelial cells before seeding onto the grafts. In native vessels, the EC layer prevents the adhesion of platelets and other blood components under the action of shear stress. However, under static culture conditions in a culture environment, the important antithrombogenic molecules are down-regulated, whereas undesirable procoagulant and proinflammatory molecules such as VCAM-1 and ICAM-1 are expressed (Stroncek et al. 2011). Therefore, the seeded EC lining possibly offered insufficient functional antithrombogenic protection, despite the presence of EC, because of EC phenotypic changes.

\section{Chemical Coatings of Vascular Grafts}

Various chemical moieties with antithrombogenic potential have been attached on the surfaces of decellularized vascular grafts to avoid thrombogenic failure, from covalent binding to passive surface attachment (Johnell et al. 2005; Zhu and Marchant 2006; Chuang and Masters 2009; Hwang et al. 2011; Sask 2012; Tang et al. 2012; Zheng et al. 2012; Leijon et al. 2013; Li et al. 2013; Janairo et al. 2014; Yao et al. 2014; Zhu et al. 2014; Dimitrievska et al. 2015). To date, the most common approach has been the covalent attachment of heparin. Part of this motivation has been the easy availability of heparin as a clinical-grade anticoagulant, although the clinical success of heparin-coated synthetic vascular grafts such as Propaten has been limited (Lindholt et al. 2011; Silvetti et al. 2015). Typically, heparin is attached in an oriented manner, allowing access to antithrombin-III in the blood, which confers its biological activity (Dorigo et al. 2011; Lindholt et al. 2011).

Synthetic grafts offer a surface that is resilient to harsh chemical treatments, allowing controlled chemical coating attachment, such as oriented heparin. On the other hand, decellularized grafts are susceptible to damage from nonpolar solvents, low/high $\mathrm{pH}$, and nonphysiological temperatures (Dimitrievska et al. 2015). Harsh solvents induce denaturation of the ECM collagen fibers, resulting in a "melting" process of the helix-coil transition of collagen. Following collagen denaturation, the mechanical properties are damaged, and a series of undesirable inflammatory reactions can ensue in the vasculature. Hence, decellularized vascular graft coating development also means using nonaggressive treatments, which has led to the frequent use of aqueous cross-linkers. Because of the gentle nature of collagen, the cross-linkers are most commonly used, which take advantage 
Blood Vessel Developments

of random reactive end-groups within the ECM such as primary amines and carbonyl groups, and cross-linking can occur without discrimination. Various unspecific aqueous cross-linkers can be used to bind anticoagulant molecules such as heparin, polypropylene sulfide-polyethylene glycol (PEG), thrombomodulin, Hirudin, P15, and others (Lee et al. 2012). However, these gentle and nonspecific approaches have resulted in low binding of the antithrombogenic molecules of interest, with consequent collagen exposure to the bloodstream. Lack of control over the antithrombogenic molecules' orientation, in combination with small amounts of attachment/coverage, have been the main reasons for limited success following chemical immobilization of heparin and other antithrombogenic molecules on decellularized vascular grafts (Lee et al. 2012; Dimitrievska et al. 2015).

Of the many strategies under development, amplification of the coated molecule of interest and deposition in an oriented manner are strategies under development by various groups. Among the approaches, our method enables the amplification of the molecule of interest in an oriented fashion by taking advantage of a bio-orthogonal click-coated oriented heparincontaining layer (Fig. 5). The underlying theory behind this approach is that the amplification of anchoring amine molecules in a radial carbohydrate structure would create a continuous layer of molecules shielding the thrombogenic collagen from the bloodstream. In other words, each primary amine anchor point is amplified into 10 potential binding sites, using the azide-clickable dendrons. In addition, such an approach also allows the re-creation of a surface similar to the native glycocalyx, which expands in a brushlike manner. The azide-clickable dendrons can then be decorated with the anticoagulant molecule of choice, such heparin in this case. Furthermore, the sophisticated chemistry allows the deposition of the molecule of interest in

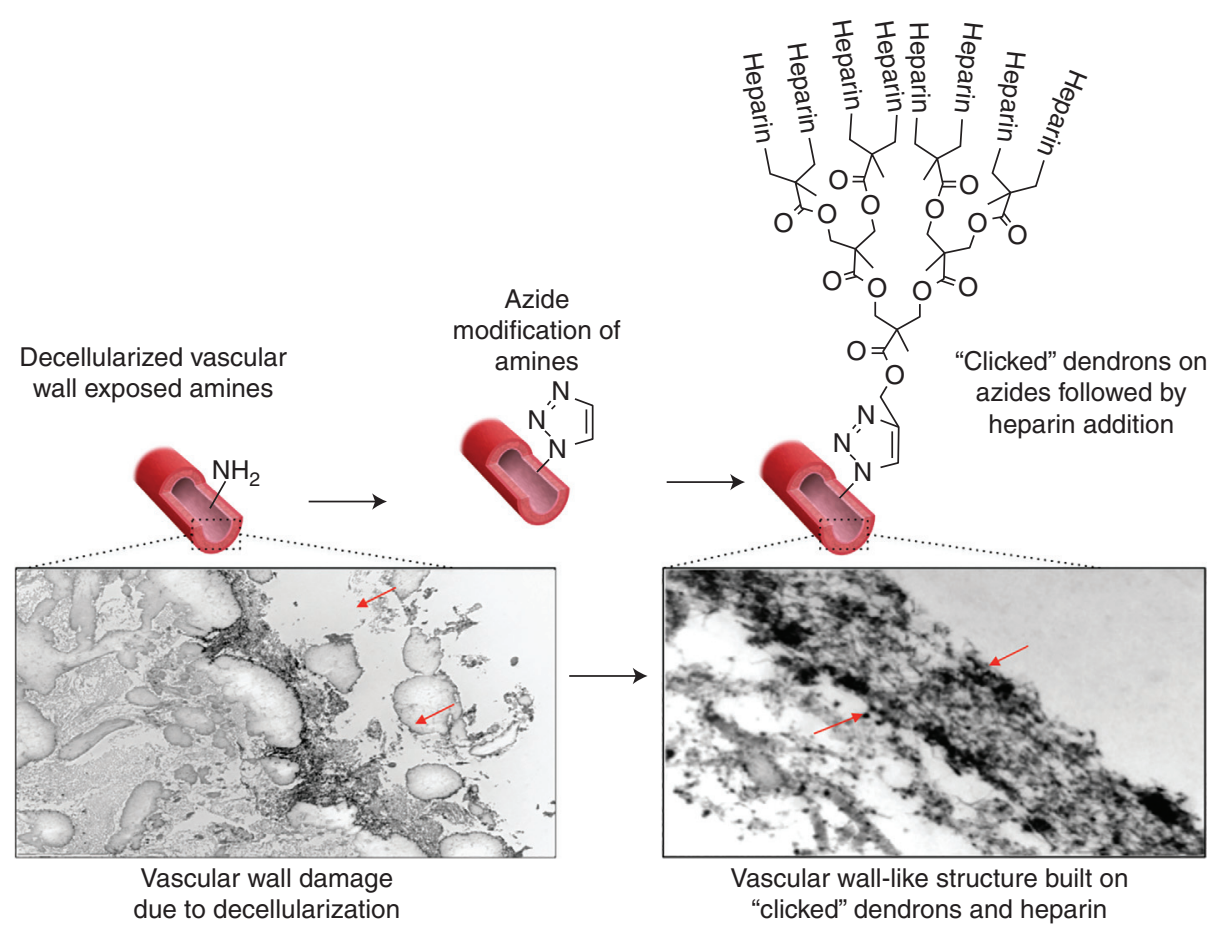

Figure 5. Novel approaches for synthetic coatings of decellularized vessels to ensure an antithrombogenic surface. The coating amplifies the molecules that shield the thrombogenic collagenous structure of the collagen and create a surface similar to the native glycocalyx, which expands in a brush-like manner. 
an oriented fashion much like the orientation of heparan sulfate on the EC surface glycocalyx (Dimitrievska et al. 2015).

\section{CONCLUSION}

Development of a mechanically robust and biologically appropriate vascular graft is extremely challenging. From a clinical perspective, consideration of time to produce the grafts and total costs are imperative for the creation of a clinically viable technology. To date, the most successful approaches have used either decellularized native tissues, or used differentiated vascular cells to culture an engineered tissue. Tissue-engineering approaches still require long times for generation of TEVGs. Both native and tissue-engineered decellularized vascular grafts still suffer from thrombogenicity issues as the primary cause of failure postimplantation.

\section{ACKNOWLEDGMENTS}

The authors thank Katherine Li for her help in design of some of the illustrations used in this work.

\section{REFERENCES}

Assmann A, Delfs C, Munakata H, Schiffer F, Horstkötter K, Huynh K, Barth M, Stoldt VR, Kamiya H, Boeken U, et al. 2013. Acceleration of autologous in vivo recellularization of decellularized aortic conduits by fibronectin surface coating. Biomaterials 34: 6015-6026.

Baumann BC, Forte P, Hawley RJ, Rieben R, Schneider MK, Seebach JD. 2004. Lack of galactose-alpha-1,3-galactose expression on porcine endothelial cells prevents complement-induced lysis but not direct xenogeneic NK cytotoxicity. J Immunol 172: 6460-6467.

Belkin S, Endo I, Mattiasson B, Nielsen J, Stephanopoulos G, Tsao GT, Ulber R, Zhou W. 2010. Advances in biochemical engineering/biotechnology. Springer, Heidelberg.

Bhattacharya V, McSweeney PA, Shi Q, Bruno B, Ishida A, Nash R, Storb RF, Sauvage LR, Hammond WP, Wu MH. 2000. Enhanced endothelialization and microvessel formation in polyester grafts seeded with $\mathrm{CD} 34^{+}$bone marrow cells. Blood 95: 581-585.

Chuang TW, Masters KS. 2009. Regulation of polyurethane hemocompatibility and endothelialization by tethered hyaluronic acid oligosaccharides. Biomaterials 30: 5341-5351.

Cittadella G, de Mel A, Dee R, De Coppi P, Seifalian AM. 2013. Arterial tissue regeneration for pediatric applica- tions: Inspiration from up-to-date tissue-engineered vascular bypass grafts. Artif Organs 37: 423-434.

Dahl SL, Kypson AP, Lawson JH, Blum JL, Strader JT, Li Y, Manson RJ, Tente WE, DiBernardo L, Hensley MT, et al. 2011. Readily available tissue-engineered vascular grafts. Sci Transl Med 3: 68ra9.

de Mel A, Cousins BG, Seifalian AM. 2012. Surface modification of biomaterials: A quest for blood compatibility. Int J Biomater 2012: 707863.

Derham C, Yow H, Ingram J, Fisher J, Ingham E, Korrosis SA, Homer-Vanniasinkam S. 2008. Tissue engineering small-diameter vascular grafts: Preparation of a biocompatible porcine ureteric scaffold. Tissue Eng Part A 14: 1871-1882.

Deutsch M, Meinhart J, Zilla P, Howanietz N, Gorlitzer M, Froeschl A, Stuempflen A, Bezuidenhout D, Grabenwoeger M. 2009. Long-term experience in autologous in vitro endothelialization of infrainguinal ePTFE grafts. $J$ Vasc Surg 49: 352-62.

Dimitrievska S, Cai C, Weyers A, Balestrini JL, Lin T, Sundaram S, Hatachi G, Spiegel DA, Kyriakides TR, Miao J, et al. 2015. Click-coated, heparinized, decellularized vascular grafts. Acta Biomater 13: 177-87.

Dohmen PM, Lembcke A, Hotz H, Kivelitz D, Konertz WF. 2002. Ross operation with a tissue-engineered heart valve. Ann Thorac Surg 74: 1438-1442.

Dohmen PM, Lembcke A, Holinski S, Kivelitz D, Braun JP, Pruss A, Konertz W. 2007. Mid-term clinical results using a tissue-engineered pulmonary valve to reconstruct the right ventricular outflow tract during the Ross procedure. Ann Thorac Surg 84: 729-736.

Dorigo W, Pulli R, Castelli P, Dorrucci V, Ferilli F, De Blasis G, Monaca V, Vecchiati E, Pratesi C; Propaten Italian Registry G. 2011. A multicenter comparison between autologous saphenous vein and heparin-bonded expanded polytetrafluoroethylene (ePTFE) graft in the treatment of critical limb ischemia in diabetics. J Vasc Surg 54: 1332 1338.

Fauvel-Lafève F. 1999. Microfibrils from the arterial subendothelium. Int Rev Cytol 188: 1-40.

Glynn JJ, Hinds MT. 2014. Endothelial outgrowth cells: Function and performance in vascular grafts. Tissue Eng Part B Rev 20: 294-303.

Grassl ED, Oegema TR, Tranquillo RT. 2003. A fibrin-based arterial media equivalent. J Biomed Mater Res A 66: 550561.

Hartranft CA, Noland S, Kulwicki A, Holden CR, Hartranft T. 2014. Cryopreserved saphenous vein graft in infrainguinal bypass. J Vasc Surg 60: 1291-1296.

Hashi CK, Zhu Y, Yang GY, Young WL, Hsiao BS, Wang K, Chu B, Li S. 2007. Antithrombogenic property of bone marrow mesenchymal stem cells in nanofibrous vascular grafts. Proc Natl Acad Sci 104: 11915-11920.

Hawkes AL, Nowak M, Bidstrup B, Speare R. 2006. Outcomes of coronary artery bypass graft surgery. Vasc Health Risk Manag 2: 477-484.

Hwang SJ, Kim SW, Choo SJ, Lee BW, Im I, Yun HJ, Lee SK, Song H, Cho WC, Lee JW. 2011. The decellularized vascular allograft as an experimental platform for developing a biocompatible small-diameter graft conduit in a rat surgical model. Yonsei Med J 52: 227-233. 
Janairo RR, Zhu Y, Chen T, Li S. 2014. Mucin covalently bonded to microfibers improves the patency of vascular grafts. Tissue Eng Part A 20: 285-293.

Johnell M, Larsson R, Siegbahn A. 2005. The influence of different heparin surface concentrations and antithrombin-binding capacity on inflammation and coagulation. Biomaterials 26: $1731-1739$.

Kakisis JD, Liapis CD, Breuer C, Sumpio BE. 2005. Artificial blood vessel: The Holy Grail of peripheral vascular surgery. J Vasc Surg 41: 349-354.

Lee YB, Shin YM, Lee JH, Jun I, Kang JK, Park JC, Shin H. 2012. Polydopamine-mediated immobilization of multiple bioactive molecules for the development of functional vascular graft materials. Biomaterials 33: 8343-8352.

Leijon J, Carlsson F, Bra J, Sanchez J, Larsson R, Nilsson B, Magnusson PU, Rosenquist M. 2013. Attachment of flexible heparin chains to gelatin scaffolds improves endothelial cell infiltration. Tissue Eng Part A 19: 1336-1349.

Li X, Luan S, Yuan S, Song L, Zhao J, Ma J, Shi H, Yang H, Jin J, Yin J. 2013. Surface functionalization of styrenic block copolymer elastomeric biomaterials with hyaluronic acid via a "grafting to" strategy. Colloids Surf B Biointerfaces 112: $146-154$.

Lindholt JS, Gottschalksen B, Johannesen N, Dueholm D, Ravn H, Christensen ED, Viddal B, Florenes T, Pedersen G, Rasmussen M, et al. 2011. The Scandinavian Propaten trial-1-year patency of PTFE vascular prostheses with heparin-bonded luminal surfaces compared to ordinary pure PTFE vascular prostheses-A randomised clinical controlled multi-centre trial. Eur J Vasc Endovasc Surg 41: 668-673.

McAllister TN, Maruszewski M, Garrido SA, Wystrychowski W, Dusserre N, Marini A, Zagalski K, Fiorillo A, Avila H, Manglano X, et al. 2009. Effectiveness of haemodialysis access with an autologous tissue-engineered vascular graft: A multicentre cohort study. Lancet 373: 1440 1446.

McFetridge PS, Daniel JW, Bodamyali T, Horrocks M, Chaudhuri JB. 2004. Preparation of porcine carotid arteries for vascular tissue engineering applications. J Biomed Mater Res A 70: 224-234.

McKee JA, Banik SSR, Boyer MJ, Hamad NM, Lawson JH, Niklason LE, Counter CM. 2003. Human arteries engineered in vitro. EMBO Rep 4: 633-638.

Mironov V, Kasyanov V, Zheng Shu X, Eisenberg C, Eisenberg L, Gonda S, Trusk T, Markwald RR, Prestwich GD. 2005. Fabrication of tubular tissue constructs by centrifugal casting of cells suspended in an in situ crosslinkable hyaluronan-gelatin hydrogel. Biomaterials 26: 76287635.

Mount C, Dusserrre N, Mcallister T, Heureux NL. 2014. Tissue-engineered cardiovascular grafts and novel applications of tissue engineering by self-assembly (TESATM). Woodhead, Cambridge.

Mozaffarian D, Benjamin EJ, Go AS, Arnett DK, Blaha MJ, Cushman M, de Ferranti S, Després JP, Fullerton HJ, Howard VJ, et al. 2014. Heart disease and stroke statistics-2015 update: A report from the American Heart Association. Circulation 131: e29-e322.

Narita Y, Kagami H, Matsunuma H, Murase Y, Ueda M, Ueda Y. 2008. Decellularized ureter for tissue-engineered small-caliber vascular graft. J Artif Organs 11: 91-99.
Owens CD, Gasper WJ, Rahman AS, Conte MS. 2015. Vein graft failure. J Vasc Surg 61: 203-216.

Pennel T, Fercana G, Bezuidenhout D, Simionescu A, Chuang TH, Zilla P, Simionescu D. 2014. The performance of cross-linked acellular arterial scaffolds as vascular grafts: Pre-clinical testing in direct and isolation loop circulatory models. Biomaterials 35: 6311-6322.

Quint C, Kondo Y, Manson RJ, Lawson JH, Dardik A, Niklason LE. 2011. Decellularized tissue-engineered blood vessel as an arterial conduit. Proc Natl Acad Sci 108: 9214-9219.

Rees MD, Kennett EC, Whitelock JM, Davies MJ. 2008. Oxidative damage to extracellular matrix and its role in human pathologies. Free Radic Biol Med 44: 1973-2001.

Reitsma S, Slaaf DW, Vink H, van Zandvoort MA, oude Egbrink MG. 2007. The endothelial glycocalyx: Composition, functions, and visualization. Pflugers Arch 454: $345-359$.

Sask KN. 2012. Antithrombogenic biomaterials: Surface modification with an antithrombin-heparin covalent complex. Acta Biomater 6: 2911-2919.

Seifu DG, Purnama A, Mequanint K, Mantovani D. 2013. Small-diameter vascular tissue engineering. Nat Rev Cardiol 10: 410-21.

Silvetti S, Koster A, Pappalardo F. 2015. Do we need heparin coating for extracorporeal membrane oxygenation? New concepts and controversial positions about coating surfaces of extracorporeal circuits. Artif Organs 39: 176-179.

Simionescu DT, Lu Q, Song Y, Lee JS, Rosenbalm TN, Kelley C, Vyavahare NR. 2006. Biocompatibility and remodeling potential of pure arterial elastin and collagen scaffolds. Biomaterials 27: 702-713.

Simionescu A, Schulte JB, Fercana G, Simionescu DT. 2011. Inflammation in cardiovascular tissue engineering: The challenge to a promise: A minireview. Int J Inflam 2011: 958247.

Simon P, Kasimir MT, Seebacher G, Weigel G, Ullrich R, Salzer-Muhar U, Rieder E, Wolner E. 2003. Early failure of the tissue engineered porcine heart valve SYNERGRAFT in pediatric patients. Eur J Cardiothorac Surg 23: $1002-1006$.

Stapleton TW, Ingram J, Katta J, Knight R, Korossis S, Fisher J, Ingham E. 2008. Development and characterization of an acellular porcine medial meniscus for use in tissue engineering. Tissue Eng Part A 14: 505-518.

Stroncek JD, Xue Y, Haque N, Lawson JH, Reichert WM. 2011. In vitro functional testing of endothelial progenitor cells that overexpress thrombomodulin. Tissue Eng Part A 17: 2091-2100.

Syedain ZH, Meier LA, Bjork JW, Lee A, Tranquillo RT. 2011. Implantable arterial grafts from human fibroblasts and fibrin using a multi-graft pulsed flow-stretch bioreactor with noninvasive strength monitoring. Biomaterials 32: 714-722.

Tang M, Xue J, Yan K, Xiang T, Sun S, Zhao C. 2012. Heparin-like surface modification of polyethersulfone membrane and its biocompatibility. J Colloid Interface Sci 386: $428-440$.

Teebken OE, Haverich A. 2002. Tissue engineering of small diameter vascular grafts. Eur J Vasc Endovasc Surg 23: $475-485$. 
S. Dimitrievska and L.E. Niklason

Teebken OE, Bader A, Steinhoff G, Haverich A. 2000. Tissue engineering of vascular grafts: Human cell seeding of decellularised porcine matrix. Eur J Vasc Endovasc Surg 19: $381-386$.

van den Berg BM, Nieuwdorp M, Stroes ESG, Vink H. 2006. Glycocalyx and endothelial (dys) function: From mice to men. Pharmacol Rep 58: 75-80.

Walles T, Puschmann C, Haverich A, Mertsching H. 2003. Acellular scaffold implantation-No alternative to tissue engineering. Int J Artif Organs 26: 225-234.

Weinberg CB, Bell E. 1986. A blood vessel model constructed from collagen and cultured vascular cells. Science 231: 397-400.

Wystrychowski W, McAllister TN, Zagalski K, Dusserre N, Cierpka L, L'Heureux N. 2014. First human use of an allogeneic tissue-engineered vascular graft for hemodialysis access. J Vasc Surg 60: 1353-1357.

Yang MC, Chi NH, Chou NK, Huang YY, Chung TW, Chang YL, Liu HC, Shieh MJ, Wang SS. 2010. The influence of rat mesenchymal stem cell CD44 surface markers on cell growth, fibronectin expression, and cardiomyogenic dif- ferentiation on silk fibroin-hyaluronic acid cardiac patches. Biomaterials 31: 854-862.

Yao Y, Wang J, Cui Y, Xu R, Wang Z, Zhang J, Wang K, Li Y, Zhao Q, Kong D. 2014. Effect of sustained heparin release from PCL/chitosan hybrid small-diameter vascular grafts on anti-thrombogenic property and endothelialization. Acta Biomater 10: 2739-2749.

Zehr KJ, Yagubyan M, Connolly HM, Nelson SM, Schaff HV. 2005. Aortic root replacement with a novel decellularized cryopreserved aortic homograft: Postoperative immunoreactivity and early results. J Thorac Cardiovasc Surg 130: 1010-1015.

Zheng W, Wang Z, Song L, Zhao Q, Zhang J, Li D, Wang S, Han J, Zheng XL, Yang Z, et al. 2012. Endothelialization and patency of RGD-functionalized vascular grafts in a rabbit carotid artery model. Biomaterials 33: 2880-2891.

Zhu J, Marchant RE. 2006. Dendritic saccharide surfactant polymers as antifouling interface materials to reduce platelet adhesion. Biomacromolecules 7: 1036-1041.

Zhu C, Fan D, Wang Y. 2014. Human-like collagen/hyaluronic acid 3D scaffolds for vascular tissue engineering. Mater Sci Eng C Mater Biol Appl 34: 393-401. 


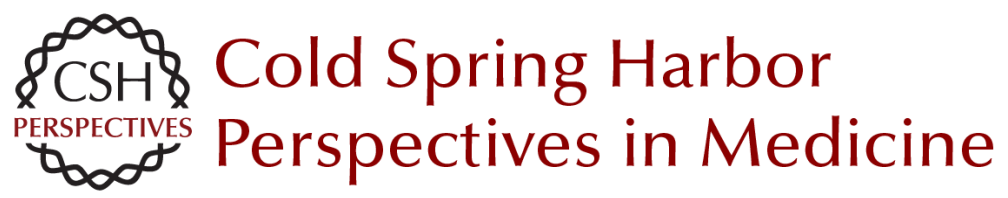

\title{
Historical Perspective and Future Direction of Blood Vessel Developments
}

\author{
Sashka Dimitrievska and Laura E. Niklason
}

Cold Spring Harb Perspect Med 2018; doi: 10.1101/cshperspect.a025742 originally published online March 27, 2017

\section{Subject Collection Tissue Engineering and Regenerative Medicine}

The Heart and Great Vessels

Ekene Onwuka, Nakesha King, Eric Heuer, et al.

Three-Dimensional Bioprinting Strategies for Tissue Engineering

Yu Shrike Zhang, Rahmi Oklu, Mehmet Remzi Dokmeci, et al.

Honing Cell and Tissue Culture Conditions for Bone and Cartilage Tissue Engineering Johnny Lam, Esther J. Lee, Elisa C. Clark, et al.

Tissue Engineering Functional Gastrointestinal Regions: The Importance of Stem and Progenitor Cells

Andrew Trecartin and Tracy Grikscheit

\author{
Historical Perspective and Future Direction of \\ Blood Vessel Developments \\ Sashka Dimitrievska and Laura E. Niklason \\ Craniofacial Tissue Engineering \\ Weibo Zhang and Pamela Crotty Yelick
}

The Self-Assembling Process and Applications in Tissue Engineering

Jennifer K. Lee, Jarrett M. Link, Jerry C.Y. Hu, et al.

Biologic Scaffolds

Alessandra Costa, Juan Diego Naranjo, Ricardo Londono, et al.

For additional articles in this collection, see http://perspectivesinmedicine.cshlp.org/cgi/collection/ 